Research Article

Donato Abruzzese, Davide Bracale, Damiano Forconi, Gian Marco Grizzi, Andrea Micheletti*, Daniele Paradisi, Alessandro Tiero, and Sreymom Vuth

\title{
Permanent monitoring of thin structures with low-cost devices $^{\star *}$
}

https://doi.org/10.1515/cls-2021-0018

Received Oct 14, 2020; accepted Feb 25, 2021

Abstract: Recently, structural monitoring technology invested in methodologies that give direct information on structures' stress state. Optic fibers, strain gauges, pressure cells give real-time data on the stress condition of a structural element, often determining the area where peak stresses have been reached, with a clear advantage over other less direct monitoring methodologies, such as, e.g., the use of accelerometers and inverse analysis to estimate internal forces. In addition, stresses can be recorded in a data $\log$ for analysis after a loading event, as well as for taking into account the lifelong stress state of the structure. Beams and columns of a reinforced concrete frame can be effectively monitored for flexural loads. Differently, thin shells are most of their lifespan under membrane regime, and, when properly designed, they rarely move to the bending regime. Our proposal is to monitor the stress in thin structures by small-sized low-cost devices able to record the stress history at key locations, sending alerts when necessary, with the aim of ensuring safety against the risk of collapse, or simply to perform maintenance/repairing activities. Such devices are realized with cheap off-the-shelf electronics and traditional strain gauges. The application examples are given as laboratory tests performed on a reinforced concrete plate, a masonry panel, and a steel beam. Results shows that the permanent monitoring control of stresses can be conveniently carried out on new structures using low-cost devices of the type we designed and realized in-house.

Keywords: structural health monitoring, new constructions, permanent monitoring, stress measurement, lowcost sensors

\footnotetext{
*Corresponding Author: Andrea Micheletti: Department of Civil and Computer Sciences Engineering, University of Rome Tor Vergata, Rome, Italy; Email: micheletti@ing.uniroma2.it

Donato Abruzzese, Davide Bracale, Damiano Forconi, Gian Marco Grizzi, Daniele Paradisi, Alessandro Tiero, Sreymom Vuth: Department of Civil and Computer Sciences Engineering, University of Rome Tor Vergata, Rome, Italy
}

\section{Introduction}

The monitoring of structures has been always a demand more than a suggestion of structural designers, even though the owners are often afraid about the installation cost of expensive devices with a not completely clear and reliable efficiency. Indeed, construction experts and builders would much like to have a continuous real-time picture of the structure's conditions, and if a reliable structural health control system could be available, they would use it. There are at least two motivations which brought people to refrain from installing complicated electronics devices on a structure. One is the belief that structural 'damages' are not so menacing and impending on our life; the other one is the difficulty to understand the real 'daily' advantages of such an electronic system, which could be embedded and hidden in our steel or reinforced concrete homes, hospitals, factories, theatres, commercial centers, etc.

In fact, a permanent monitoring system would provide an up-to-date information on the condition of the structure, like the one we get from our car dashboard every day, and in the same way could send an alert in case of problem, whether the situation is critical or not, suggesting us what part of the structure is suffering. It is the same approach followed in the design of the car sensors and checking system that put us in the safest possible driving condition. Monitoring of structures, or structural health monitoring (SHM), has followed the development of modern electronics, trying to take advantage of its typical positive aspects: miniaturization of components, which allows for the use of sensors and devices embedded in the structure or with negligible size; communication via different platforms, such as Wi-Fi, Bluetooth, high frequency radio; large dissemination of more friendly electronic components which do not require, in most cases, a strong experience as electronic engineer.

Wireless sensor networks (WSN) have been considered to obtain effective SHM systems for a long time. In [1], a

\footnotetext{
$\star \star$ Paper included in the Special Issue entitled: Shell and Spatial Structures: Between New Developments and Historical Aspects
}

๑ Open Access. ( 2021 D. Abruzzese et al., published by De Gruyter. (CC) BY This work is licensed under the Creative Commons Attribution 4.0 License 
number of wireless sensing units for SHM were reviewed. In [2], a high-precision, wireless acquisition system for accelerometers with reliable synchronization accuracy is realized and validated. In [3], a comprehensive review on WSN-based SHM systems was given. In [4], current solutions for IoT communications in SHM were surveyed. Many researchers focused on networks composed of nodes based on microelectromechanical systems (MEMS). In particular, in [5], a low-cost architecture of a wireless sensor network composed of MEMS accelerometers was proposed. In [6], wireless, low-cost MEMS accelerometers were validated on a cable-stayed bridge. In [7] the effectiveness of a MEMS pressure sensor for monitoring the stress in steel rebars was demonstrated. In [8], a continuous recording system for a low-cost station based on a MEMS accelerometer is implemented. In [9], an open-source, low-cost MEMS accelerometer were assessed through a series of comparative validation tests. Piezoelectric (PZT) sensors for acoustic emissions (AE) or impedance measurements have also been extensively researched. For example, in [10], the damage evolution of masonry mortars was evaluated by means PZT sensors and the $\mathrm{AE}$ technique, while in [11] the waitingtime distributions in AE measurements are simulated and tested. In [12], a real-time IoT platform for SHM based on PZT sensors was proposed. In [13], a multi-agent, IoT-based system is proposed exploiting acoustic emissions measured by PZT sensors. In [14], it is shown that impedance measurements via PZT sensors provide an effective and cheap solution for fracture detection on RC buildings. A few recent studies considered displacement and strain sensors. In [15], a solar-powered, wireless, low-cost device to measure crack openings along with temperature and humidity was proposed, and in [16], a wireless, low-cost system for analyzing quasi-static displacements in response to thermal loads was presented, while in [17], an SHM node for multiple types of sensors was designed and field tested. In [18], a wireless, low-power strain sensor was tested experimentally. In [19], a wireless, IoT-enabled strain sensor has been proposed for monitoring falsework safety, and in [20], a wireless, low-cost strain sensor for monitoring the stress in rebars was developed.

If at the beginning the Internet of the Things (IoT) has been used as simple additional experimental system, at present the use of multiple electronic devices allows one to design the monitoring system with specific requests, according to the typology of the structure or the individual structure element, the construction material, the stress to investigate, the static or dynamic behavior, the interval time for the registration, and, finally, the communication architecture to send the remote information to the central control point [21-24]. Despite the large number of possi- ble variables to be considered for a suitable and reliable structural control system, we can now state that the civil engineer, or structural designer, is enabled to be responsible of the design of correct SHM architectures, requiring consultancy from the electronic engineer only for limited needs. Definitely, the architecture of the monitoring system cannot be designed by electronic engineers only, since the monitoring system is related to the type of stress, location, duration, and frequency acquisition of the data. Ultimately, it is clear that the interpretation of the data, once collected in a suitable way, is a duty of the structural engineer. This is also very important, since requires a high knowledge about structures, loads, material, restraints. A good list of statement, rules and referring values (i.e., yield point of the material) will make the structural control much more efficient. Of course, the IoT electronic devices could be selected and the entire architecture could be optimized by the electronic engineers, but it is strongly suggested, if not unavoidable, that the engineers cooperate together.

Monitoring bidimensional structures is a very interesting and challenging goal for engineers. The possibility to control current stresses instantaneously, as well as accumulated stresses, for a long time, can give to the structural engineer the feeling of a permanent knowledge of the structure. We know that sometimes complicated or irregular shapes of thin shells are difficult to model, since the presence of the double curvature, for instance, implies a strict but not clear relation between the two stress directions (Figure 1). To have a permanent knowledge of the local stress in some peculiar point of the structure allows one to compare the theoretical and numerical results with the real ones expressed by the structure under loads. The continuous control of the stress, connected also to different load cases, produces an amount of information useful to adjust the relevant parameter included inside the numerical simulation, like Young elastic modulus or behavior of the restraints, and it results in a more reliable model of the reality.
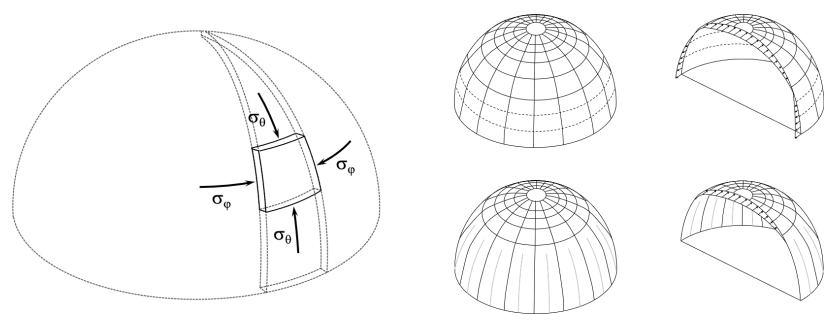

Figure 1: The typical $\sigma_{\phi}$ and $\sigma_{\theta}$ membrane stress in a shell (left). Stress in a masonry vault (right). Redrawn from [25] 


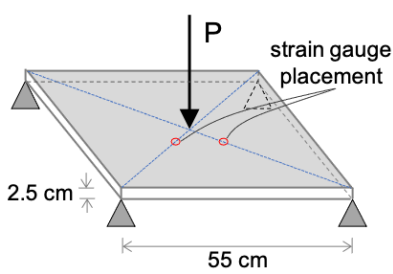

(a)

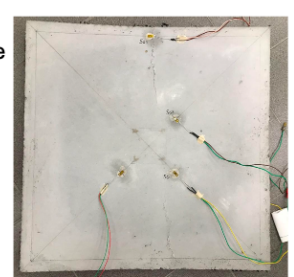

(b)

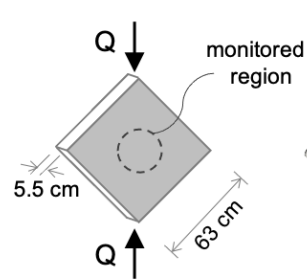

(c)

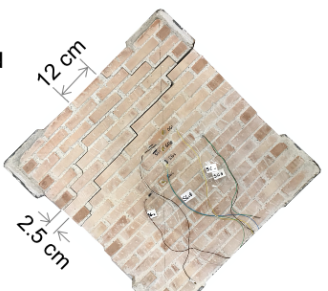

(d)

Figure 2: Five-point out-of-plane bending test (a) on an instrumented FRP reinforced concrete plate brought to fracture (b). In-plane diagonal compression test (c) on an instrumented masonry panel brought to fracture (d). (Detailed images and schematics of test setups are shown in Figures 4, 5, and 7)

In this work the application examples are given as laboratory tests performed on: a steel beam (three-point bending test), a reinforced concrete plate (bending test, Figure $2 \mathrm{a}, 2 \mathrm{~b}$ ), and a masonry panel (diagonal compression test, Figure 2c, 2d). Results shows that a permanent monitoring control of stresses can be conveniently carried out on new structures using low-cost devices of the type we designed and realized in-house. In the next section, the experimental setup of each of the test is described, together with the components' layout of the low-cost wireless sensing device proposed. Section 3 illustrates the results of the tests, while our concluding remarks follow in the last section.

\section{Experimental testing of low-cost devices}

The development of a suitable and affordable family of devices connected to the IoT for monitoring structures led us to design and realize sensors which should meet standard technical requirements and a satisfactory level of precision and reliability. Then the sensors and the connected control

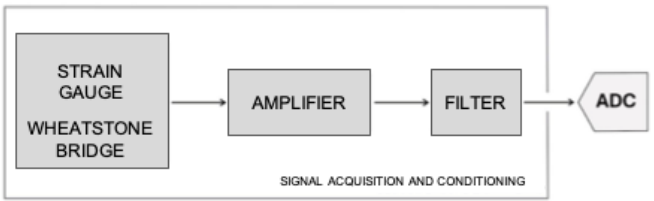

(a)

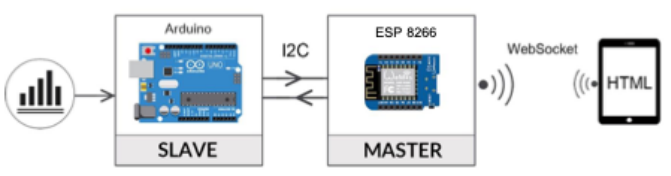

(b) device have been tested in laboratory, making performance comparisons with more conventional lab instrument, traditionally adopted for reading strain-gauge measurements. The comparative machine available in the Department of Civil and Computer Sciences Engineering at University of Rome Tor Vergata is a MGCplus from HBM Italia equipped with Catman software. In all the following tests the MGCplus device has been considered as the reference point as the most advanced and reliable machine available for such measurements. The low-cost device we present here, whose particular system architecture, assembling and programming, are designed and realized in-house, is composed by a signal acquisition/conditioning system and a processing/communication system. The signal acquisition/conditioning system (Figure 3a) is composed by two strain gauges from HBM Italia and the associated Wheatstone bridges, signal amplificators, and analog-to-digital converters, all obtained from cheap off-the-shelf components. The processing/communication system (Figure $3 b$ ) is composed by an Arduino Mega microcontroller (slave) and a ESP8266 Wi-Fi module (master). Figure 3(c) shows the web-browser graphic interface implemented on and broadcasted by the Wi-Fi module. The strain gauges employed in this study are designed to be applied in situ, and they

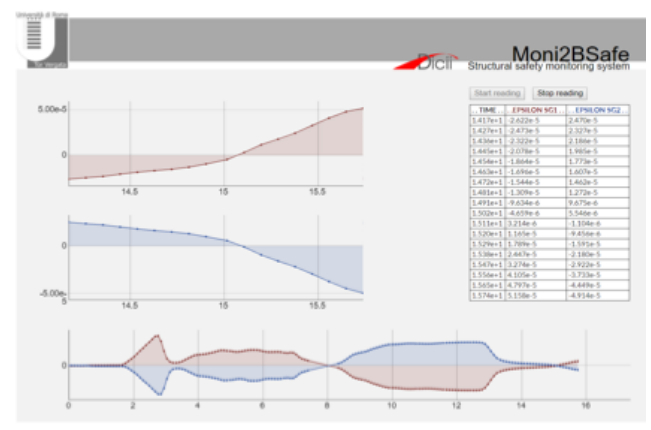

(c)

Figure 3: Low-cost device. (a) Sensor layout. (b) Communication layout. (c) Web browser interface 
are provided with temperature compensation curves which allow them to be employed, in conjunction with a matching adhesive, in a very large interval of temperatures (with maximum operational temperature ranging from $150^{\circ} \mathrm{C}$ to $300^{\circ} \mathrm{C}$, according to the type of strain gauge).

We present here three basic test setups. The first test is a standard three-point bending test carried out on a simply supported steel beam of $200 \mathrm{~cm}$ span, and $4 \times 1 \mathrm{~cm}^{2}$ rectangular cross-section, with a pair of strain gauge positioned at $5 / 12$ of the span (Figure 4a). One strain gauge has been connected to the MGCplus and the other one to the lowcost device. Following a soft-device procedure, we hang at midspan certain weights of increasing size and recorded the readings of the strain gauges at each loading step.

The second and third test have been carried out on square thin structural elements, after installation of the strain gauges at suitable positions. In both tests the load has been applied using an Instron 4482 testing machine. The second test regarded a thin square FRP concrete plate, shown in Figure 4 (b, c), supported at the corners and loaded orthogonally to the mid plane (five-point bending test). The thin plate was cast in high performance concrete (40 MPa) and reinforced by a bidirectional carbon fiber net. Two strain gauges were positioned on the top surface of the plate along the diagonals, in symmetric positions so as to compare their measurements. The third test regarded a scaled-down brick masonry panel, shown in Figure 5, tested in a shearing load case (diagonal compression test). The masonry panel did not have any reinforcement, in order to reproduce the behavior of actual masonry. Strain gauges were applied in the central region of the panel (Figure 5c), with two of them applied on the top and side brick surface at the mortar joint (SG2 and SG3, see detail in Figure 5c). Two strain gauges (SG1 and SG1a in Figure 5) were positioned along the vertical on two adjacent central bricks. The SG1 and SG1a sensors are used for the performance comparison, and they were connected to the HBM MGCplus and to the low-cost device, respectively. In order to apply the load, angular steel reinforcements for stress redistribution were attached at two opposing corners of the panel, while two steel pieces of adequate stiffness, specially designed to fit such angular reinforcement, were attached to the testing machine (see detail in Figure 5b).

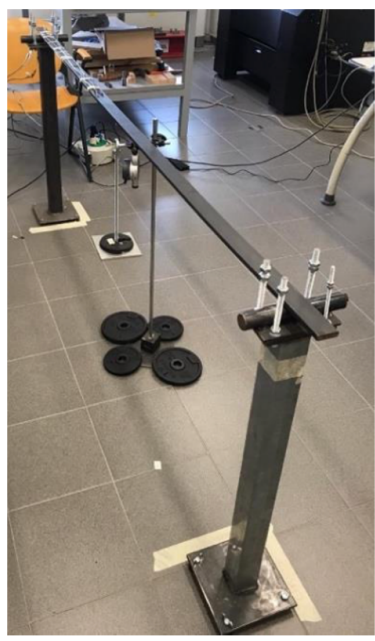

(a)

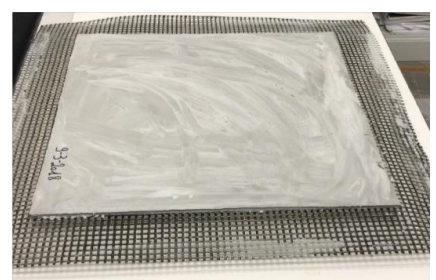

(b)

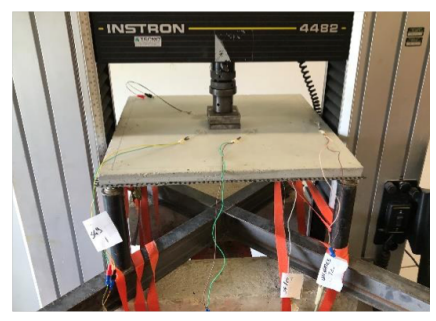

(c)
Figure 4: Three-point bending test on a simply supported steel beam (a). The realized FRP concrete square plate (b) and five-point bending test setup (c)

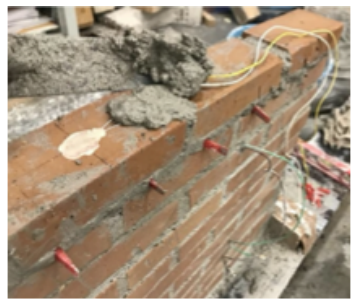

(a)

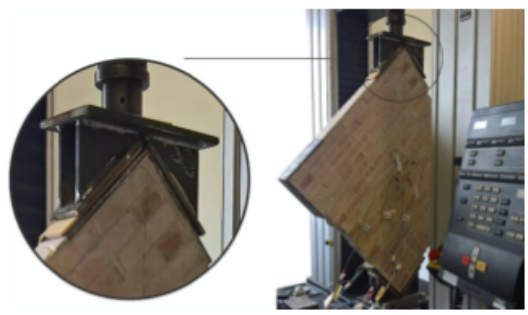

(b)

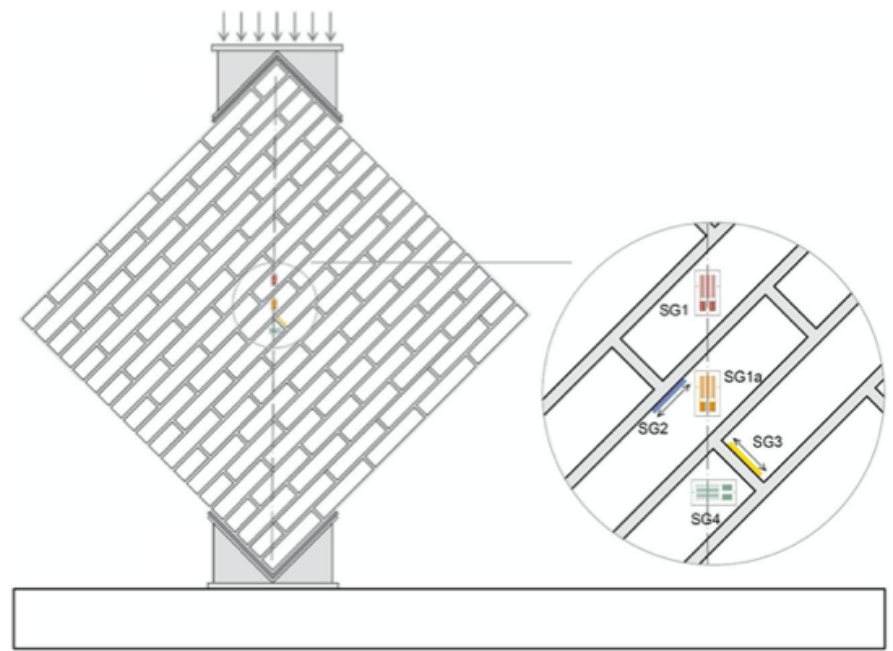

(c)

Figure 5: Realization (a) and diagonal test setup (b, c) of a reduced-scale masonry panel, together with sensors placement. The strain gauges SG1a and SG4 are read with the proposed low-cost system 


\section{Results}

The results of the three tests described in the preceding section are presented in the following tables and figures, showing a satisfactory agreement between the low-cost and the laboratory measurement instruments.

Table 1 and the plot in Figure 6 show the results of the three-point bending test on the simply supported steel beam. The difference in the measured strain values remains equal to or below 3\% except for the first three loading steps, while the absolute difference is small for all the loading steps.

Table 1: Comparison between the strain measurements of low-cost device and laboratory equipment on a simply supported steel beam

\begin{tabular}{ccccc}
\hline $\begin{array}{c}\text { Load } \\
(\mathrm{N})\end{array}$ & $\begin{array}{c}\text { L-C device } \\
\mu \mathrm{m} / \mathrm{m}\end{array}$ & $\begin{array}{c}\text { MGCPLUS } \\
\mu \mathrm{m} / \mathrm{m}\end{array}$ & $\begin{array}{c}\text { \% difference } \\
\%\end{array}$ & $\begin{array}{c}\text { Nominal } \\
\text { value } \mu \mathrm{m} / \mathrm{m}\end{array}$ \\
\hline 1.00 & 3.36 & 2.76 & $-18.0 \%$ & 2.976 \\
3.00 & 10.02 & 9.15 & $-8.7 \%$ & 8.929 \\
5.00 & 16.44 & 15.55 & $-5.4 \%$ & 14.881 \\
8.31 & 27.06 & 26.26 & $-3.0 \%$ & 24.732 \\
12.31 & 39.83 & 38.66 & $-2.9 \%$ & 36.637 \\
17.31 & 55.94 & 54.39 & $-2.8 \%$ & 51.518 \\
22.31 & 71.62 & 70.35 & $-1.8 \%$ & 66.399 \\
24.31 & 77.33 & 77.36 & $0.0 \%$ & 72.351 \\
\hline
\end{tabular}

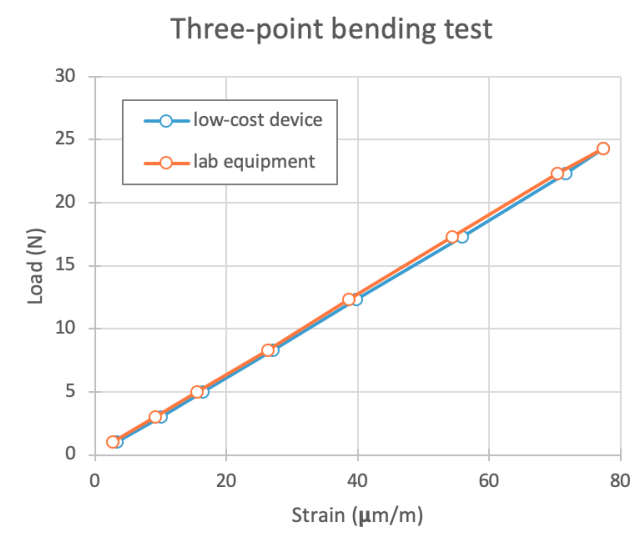

Figure 6: Comparison between the HBM MGCplus and low-cost device. Strain values for the simply supported steel beam with an increasing load applied at mid span

Figure 7(a) shows the symmetric placement of the strain gauges on the FRP concrete plate of the second test, while (b) reports the two corresponding load-vsdeformation plots recorded by the two measurement systems. One can observe that the two plots are almost superposed along the linear portion.

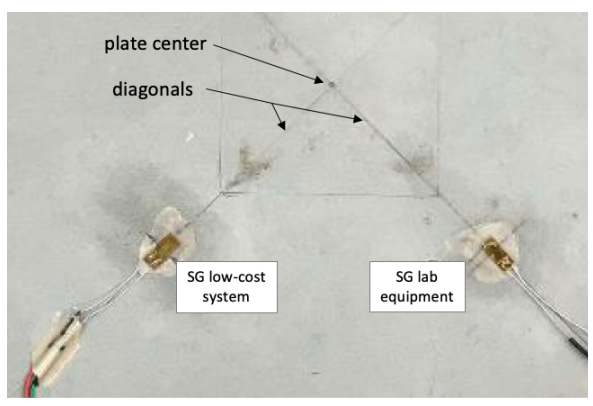

(a)

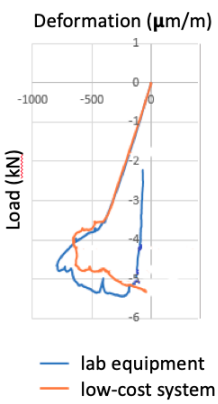

(b)
Figure 7: Results of the five-point bending test for the FR concrete plate: symmetric placement of strain gauges (a); comparison of load-vs-deformation plots (b). Measurements carried out with laboratory equipment, in blue (dark grey), and with the proposed low-cost device, in orange (light grey)

As to the results of third test, Figure 8 reports the loadvs-deformation plots for the five strain gauges installed on the masonry panel, along with the load-vs-displacement plot for this test. In particular, the SG1 and SG1a curves, corresponding to the sensors located along the main diagonal of the panel and used in the performance comparison, remain close to each other, while the visible difference between the two can be ascribed to the non-symmetric placement of the sensors. It is also worth noticing that the lowcost system was also able to detect the two cracking event which occurred during the test, as indicated by the drops in the measured strain values in curves SG1 and SG1a of Figure 8.

The experiments showed that there is a quite good agreement between the two system, a result which is promising for future research and applications. The difference in results can be ascribed to the quality and accuracy of the electronic components, such as the analog signal amplifier and the analog-to-digital converter. Moreover, the values of the measurements obtained with the low-cost device developed in-house as compared to the ones obtained with the HBM MGCplus reference lab equipment, show that there is a very limited error, taking into account in particular that the laboratory data acquisition system has a cost of the order of the tens of thousands of Euro, while our low-cost system has a cost of the order of hundreds of Euro, thus with a ratio between the costs of the two systems of the order of $1 / 100$, a result which is in agreement with the ones of other low-cost systems found in the literature [15-20]. 


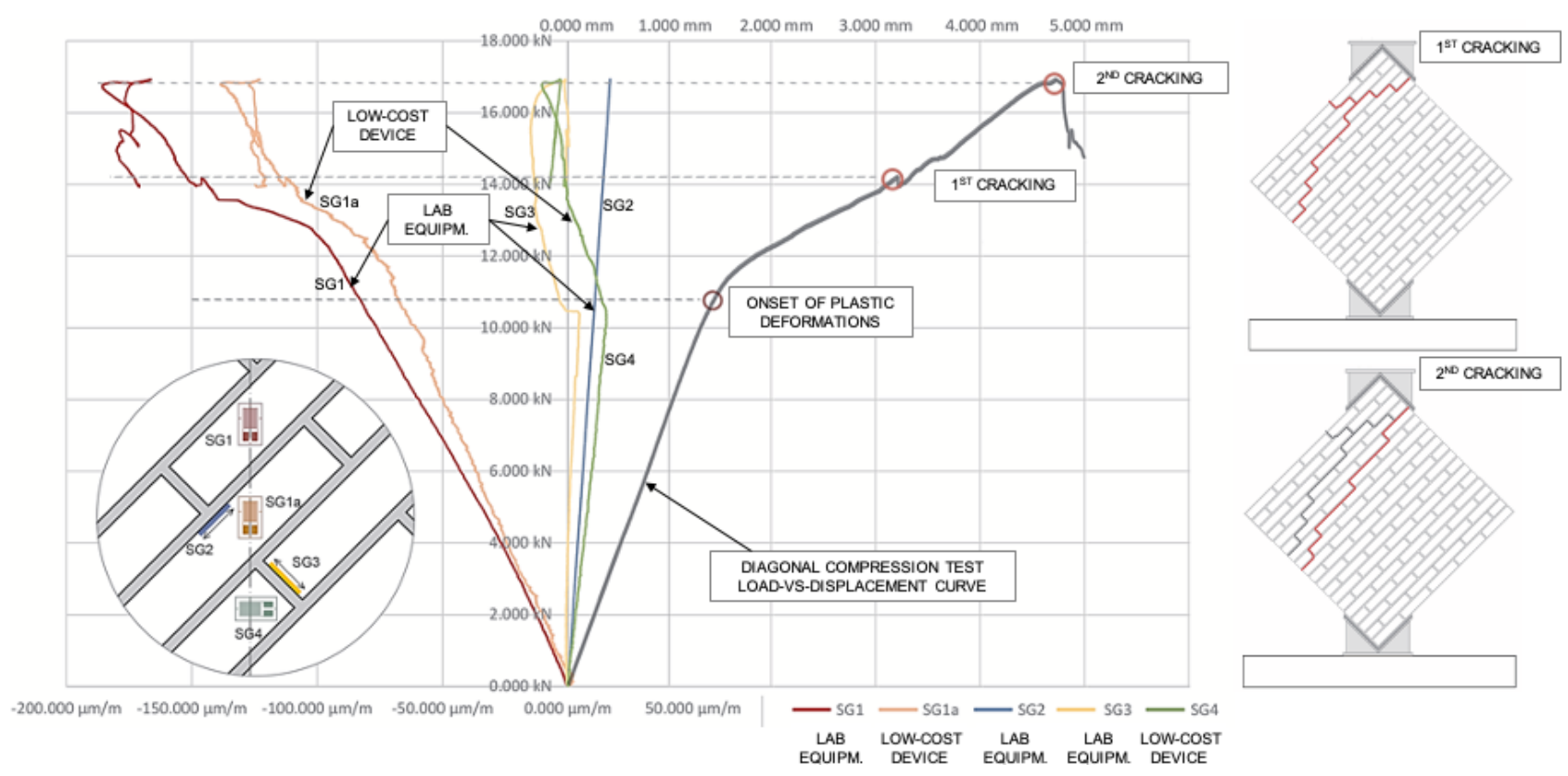

Figure 8: Results of the diagonal compression test of a reduced-scale masonry panel

\section{Concluding remarks}

Our main goal is the installation of embedded deformation sensors inside concrete shells, for instance, but not far from the inner and outer skin (Figure 9). By placing two sensor near the inner and outer skin, the in-plane internal force and the bending moment in a certain direction can be recorded. But by using also new types of sensor at the mid shell surface, which are able to measure the local curvature of the thin shell, such as the one shown in Figure 9 (top), we could get the local bending moment with a single sensor. Moreover, by installing two sensors along two directions, we would be able to obtain the bending moment along these directions.

Compact actuators enlarge the sensory capabilities of SHM. The new piezo-actuators available nowadays [2628] are based on multilayer piezo plates with cost-effective copper inner electrodes. When activated, the piezo plates expand only slightly along the $\mathrm{z}$ axis, but, owing to the constant volume deformation in the piezoelectric effect, such plates contract simultaneously along both the $\mathrm{x}$ and y axes, providing information about membrane stress but also about flexural behavior of the structure.

Sensors like that belong to the family of the piezoelectric haptic actuators (Figures 9, 10). This kind of sensor can work as actuator as well as sensor. In the latter case they can inform us about deformation, which in this case could be the curvature. From the curvature we can recover the local moment, according to the geometry of the structural

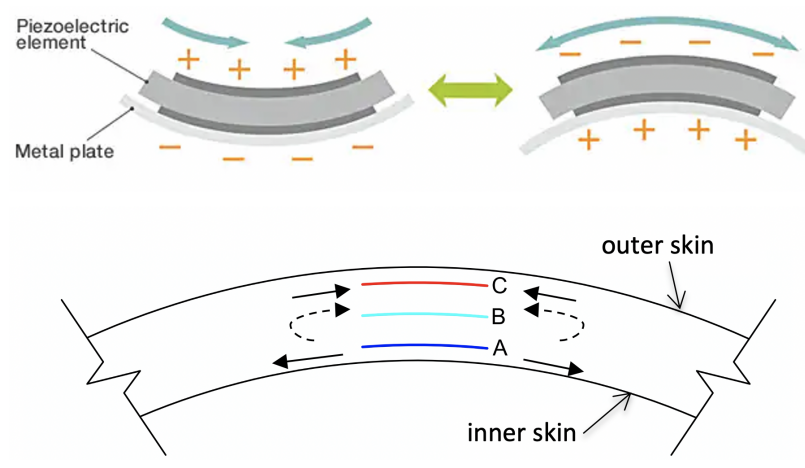

Figure 9: Top: piezo actuator (PiezoHapt ${ }^{\mathrm{TM}}$, TDK courtesy). Bottom: cross section of concrete thin shell. $A$ and $C$ are deformation sensors measuring the local in-plane normal stress; $B$ is a sensor measuring the local curvature of the thin shell
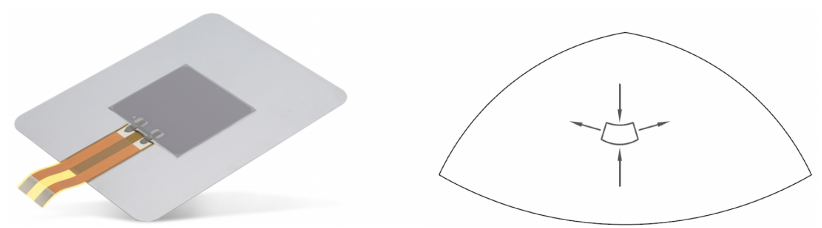

Figure 10: New thin piezo Haptic actuator (TDK courtesy) for flexural applications (left). Possible application point of the piezo-haptic actuator/sensor on a double curvature shell (right)

element. It is quite clear, at this point, what kind of monitoring information we could retrieve with this family of sensors. From the standard deformation sensor, we can achieve the membrane stress, which should be the most important stress in a thin shell; from the piezo-haptic actu- 
ators we can get information about the additional, usually of small entity but also very important, bending moments.

Figure 11 shows the famous TWA terminal in New York, by Eero Saarinen (1962). It is a marvelous example of a double curvature shell, quite difficult to analyze unless using finite element modeling, since simplified procedures and simulations could not be satisfactory. Then a good distribution of sensors as mentioned above could give local information on the shell stress and describe instantly but also permanently the real behavior of the structure. It is evident that real-time measurements could help even the structural designer to better calibrate the numerical finite element model, in order to make its predictions more reliable.

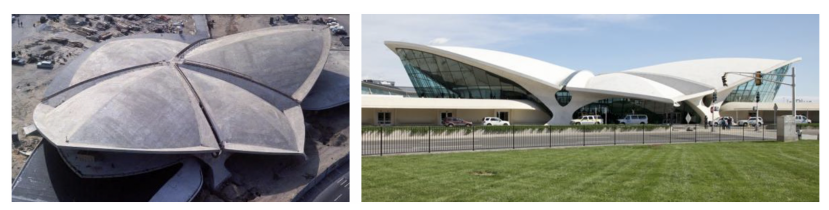

Figure 11: The TWA terminal in New York, by Eero Saarinen (1962)

The large use of structural health monitoring systems achieves two main goals: improving maintenance and increasing safety of the whole structural system. Today it is mandatory to install alerting devices on cars, instruments and other tools, in order to help preventing damage to people and goods. We are surrounded by green and red leds informing us about whether a situation is safe or not. We also often have some acoustic alarm to alert us about the danger. The question is, why we cannot use the same approach for structures, in steel or reinforced concrete, in order to improve the safety of our homes, offices, and service and entertainment buildings? And if for one second we want to forget about safety, what about maintenance? We know that if we buy a car, after several thousand kilometers we need to change the tires, and perform a small or large maintenance activity, with car technicians. This means to increase the safety, of course, but it also means that if we do not perform the maintenance activity at the right moment (when the green light becomes orange, for instance) we know that the damage will become bigger and the maintenance cost will increase. Therefore, the duty of a well-designed monitoring system is to inform us about buildings' structural health, about which structural elements need to be checked more carefully, to suggest when the structure needs to be repaired and where, and finally to increase the global safety of the construction.

Among traditional, and often not feasible, structure's control techniques we can include the embedded electronic monitoring systems consisting mainly in deformation sensors which provide information about local stresses, also recordable as permanent information on the lifelong stress condition of the structure. A suitable structural monitoring system, a corresponding well dimensioned communication system and a stress database will definitely provide an increasing value of the construction, and a comfortable safety level. Such low-cost devices and sensors and the related control panel are now really affordable and limited to about $1-2 \%$ of the cost of the entire structure, according to our estimates.

In this work, we analyzed and demonstrated the application of a low-cost SHM system to a concrete thin plate and a masonry panel at a laboratory scale, and we are currently in the process of validating the proposed device in situ. The system can be used in conjunction with other complementary non-destructive methods, such as accelerometric systems and acoustic emission systems (see, e.g., [10], and the literature cited therein). Thin shells, and mostly concrete thin shells, are still a way for the architects to express the freedom of the architectural composition, resulting in eye-catching complex shapes. These are difficult to analyze with standard models but require shape modeling software and tailored finite element structural codes. Needless to say, these considerations about SHM can be extended to other, different, types of structures adopting appropriate devices and control software.

Acknowledgement: The authors wish to thank the laboratory technician Ferdinando Miele for his passionate work and experienced assistance on the test setups. This study was partly carried out when DF and GMG were working on their MS theses, and when DB and DP were working on their BS theses, at University of Rome Tor Vergata. The contribution to this work given by former students Manuel Cosentino and Gianluca Scarano is also gratefully acknowledged. Finally, the authors wish to thank the anonymous reviewers for their comments, which contributed to improve the quality of this paper.

Funding information: This research was partly supported by the University of Rome Tor Vergata and the Department of Civil Engineering and Computer Sciences of the same university within the funding program "Mission Sustainability", project title "Structural safety monitoring system and structure-embedded event log system for new and existing buildings" (project id \# E86C18000340005).

Author contributions: All authors have accepted responsibility for the entire content of this manuscript and approved its submission. 
Conflict of interest: The authors state no conflict of interest.

\section{References}

[1] Lynch JP. An overview of wireless structural health monitoring for civil structures. Philos Trans- Royal Soc, Math Phys Eng Sci. 2007 Feb;365(1851):345-72.

[2] Araujo A, Tirado F, Palacios JG, Blesa J, Romero E, Lutz M, et al. High precision structural health monitoring system using wireless sensor networks. Proc 3rd Int Symp Life-Cycle Civ Eng, Vienna, Austria; 2012.

[3] Tokognon C, Gao B, Tian GY. Senior Member, Yan Y., Structural health monitoring framework based on internet of things: a survey. IEEE Internet Things J. 2017;4(3):619-35.

[4] Noel AB, Elfouly T, Ahmed MH, Badawy A, Shehata MS. Structural health monitoring using wireless sensor networks: a comprehensive survey. IEEE Comm Surv and Tutor. 2017;19(3):1403-23.

[5] Giammarini M, Isidori D, Pieralisi M, Cristalli C, Fioravanti M, Concettoni $\mathrm{E}$. Design of a low cost and high performance wireless sensor network for structural health monitoring. Microsyst Technol. 2016;22(7):1845-53.

[6] Bedon C, Bergamo E, Izzi M, Noè S. Prototyping and validation of MEMS accelerometers for structural health monitoring - the case study of the pietratagliata cable-stayed bridge. J. Sens. Actuator Netw. 2018;7(3):30.

[7] Tondolo F, Cesetti A, Matta E, Quattrone A, Sabia D. Smart reinforcement steel bars with low-cost MEMS sensors for the structural health monitoring of RC structures. Constr Build Mater. 2018;173:740-53.

[8] Muñoz M, Guevara R, González S, Jiménez JC. Reliable data acquisition system for a low-cost accelerograph applied to structural health monitoring. J. Appl. Sci. Eng. Technol. Educ. 2020;3(2):181-94.

[9] Bravo-Haro MA, Ding X, Elghazouli AY. MEMS-based low-cost and open-source accelerograph for earthquake strong-motion. Eng Struct. 2021;230:111675.

[10] Carpinteri A, Grazzini A, Lacidogna G, Manuello A. Durability evaluation of reinforced masonry by fatigue tests and acoustic emission technique. Struct Contr Health Monit. 2014;21(6):95061.

[11] Niccolini G, Bosia F, Carpinteri A, Lacidogna G, Manuello A, Pugno N. Self-similarity of waiting times in fracture systems. Phys Rev E Stat Nonlin Soft Matter Phys. 2009 Aug;80(2 Pt 2):026101.

[12] Abdelgawad A, Yelamarthi K. Internet of things (IoT) platform for structure health monitoring. Wirel Commun Mob Comput. 2017;2017:6560797.

[13] Lamonaca F, Sciammarella PF, Scuro C, Carnì DL, Olivito RS. Synchronization of IoT layers for structural health monitoring. Proc 2018 Workshop Metrology Industry 4.0 and IoT, Brescia, Italy; 2018:89-94. https://doi.org/10.1109/METROI4.2018.8428329.
[14] Ayyildiz C, Emre Erdem H, Dirikgil T, Dugenci O, Kocak T, Altun F, et al. Structure health monitoring using wireless sensor networks on structural elements. Ad Hoc Netw. 2019;82:68-76.

[15] Basto C, Pelà L, Chacón R. Open-source digital technologies for low-cost monitoring of historical constructions. J Cult Herit. 2017;25:31-40.

[16] Smarsly K, Mthunzi EM, Hahn O, Planer J. Validation of an ultralow-cost wireless structural health monitoring system for civil infrastructure. Proc $12^{\text {th }}$ Int Workshop Struct Health Monit, Stanford, CA, USA; 2019. https://doi.org/10.12783/shm2019/32445.

[17] Malik H, Khattak KS, Wiqar T, Khan ZH, Altamimi AB. Low cost internet of things platform for structural health monitoring. Proc $22^{\text {nd }}$ Int Multitopic Conf (INMIC), Islamabad, Pakistan; 2019. https://doi.org/10.1109/INMIC48123.2019.9022801.

[18] Kumar R, Hossain A. Experimental performance and study of low power strain gauge based wireless sensor node for structure health monitoring. Wirel Pers Commun. 2018;101(3):1657-69.

[19] Lam RC, Lam LC, Li NX, Chu DL. Lee P.K.K., IoT enabled falsework monitoring system for construction safety enhancement. Proc 2019 Int Conf Comput Sci Comput Intell (CSCI), Las Vegas, NV, USA; 2019. https://doi.org/10.1109/CSCI49370.2019.00227.

[20] Silva JB, Jacintho AE, Forti NC, Pimentel LL, Branquinho OC. Development of a low cost system for structural health monitoring. Revista Matéria; 2019. [(in Portuguese)].

[21] Abruzzese D, Micheletti A, Tiero A, Cosentino M, Forconi D, Grizzi $G$, et al. IoT sensors for modern structural health monitoring. $A$ new frontier. Procedia Struct Integr. 2020;25:378-85.

[22] Tzou HS, Lee HJ, Arnold SM. Smart materials, precision sensors/actuators, smart structures, and structronic systems. Mech Adv Mater Structures. 2004;11(4-5):367-93.

[23] Panzardi E, Pozzebon A, Vignoli V, Addabbo T, Fort A, Mugnaini M. A city-scale IoT architecture for monumental structures monitoring. Measurement. 2019;131:349-57.

[24] Nižetić S, Šolić P, López-de-Ipiña González-de-Artaza D, Patrono L, Patrono L. Internet of Things (IoT): Opportunities, issues and challenges towards a smart and sustainable future. J Clean Prod. 2020 Nov;274:122877.

[25] Ottoni F. La lunga vicenda delle fabbriche cupolate. Note storiche sulla stabilità, tra dibattito e sperimentazione. PhD Thesis. University of Parma, Parma, Italy; 2008 (in Italian).

[26] Clinton YK, Liyong T, Grant PS. A review on the modelling of piezoelectric sensors and actuators incorporated in intelligent structures. J Intell Mater Syst Struct. 1998;9(1):3-19.

[27] Biqin D. Cement-based piezoelectric ceramic composites for sensor applications in civil engineering, PhD Thesis, University of Hong Kong of Science and Technology, Hong Kong, China; 2005.

[28] Wang Q, Wu N. A review on structural enhancement and repair using piezoelectric materials and shape memory alloys. Smart Mater Struct. 2011;21(1):013001. 